LETTER TO THE EDITOR

\title{
PARENTING STRESS IN CAREGIVERS OF CHILDREN WITHAUTISM SPECTRUM DISORDER (ASD)
}

It's not easy to be the parent of a child with any sort of disability. However, through my experience as a clinical psychologist, I must admit that the challenges faced by parents of children having autism are perhaps the most moving. It is undeniably stressful for parents to have a child who is even minimally different from his/her typically developing peers, with varying degrees of severity in the impairment (if any); but, research has proved that to be a parent of a child having autism spectrum disorder (ASD) can lead to acute as well as chronic stress among the caregivers ${ }^{1,2}$. Children with ASD typically present with persistent deficits in their socio-communicative interactions along with restricted and repetitive behaviours ${ }^{3}$. For parents, learning to deal with their child's impoverished communication skills and behavioral problems such as refusal to sleep and intense behavioral meltdowns can be a cause for pain and confusion ${ }^{4}$. According to an article by Zach Gouldsmith on 'Stress of parenting a child with Autism Spectrum or Related disorders' published in AAPC Publishing, several children having autism exhibit behaviors that are regarded as "unusual," and sometimes even "disturbing," which makes parents anxious about social disapproval from other parents. There appears to be a universal deficit in the knowledge and understanding that parents have about ASD, which translates into a generalized lack of acceptance of individuals with this disability than any of the others $^{5}$.

For parents, easier access to therapists and counselors, along with autism-support groups, speech and occupational therapists, and autism associations can decrease stress and increase wellbeing. Finally, I am convinced that promoting a greater public awareness about the nature of ASD could reduce some of the social stigma and misconceptions associated with this condition'.

\section{Samina Masood Haider}

Psychologist (M.Sc. Clinical Psychology)

CSLHS

Ziauddin University

\section{REFERENCES}

[1] Schieve LA, Blumberg SJ, Rice C, Visser SN, Boyle C. The relationship between autism and parenting stress. Pediatrics. Feb 2007;1 19(Suppl 1):S114-S121.

[2] Bluth K, Roberson PNE, Billen RM, Sams JM. A Stress Model for Couples Parenting Children with Autism Spectrum Disorders and the Introduction of a Mindfulness Intervention. J Fam Theory Rev. 2013 Sep; 5(3): 194-213.

[3] DSM-5 Diagnostic Criteria. 2013. Available from: https://www.autismspeaks.org/

[4] Nath S. Sleep problems in Children with Autism. Kennedy Krieger Institute. 2013 August 14. Availabl from: https://iancommunity.org/cs/simons_simplex_community/sleep_problems

[5] Gouldsmith Z. Stress of Parenting a Child with Autism Spectrum or Related Disorders. AAPC Publish ing; Jan 2015. Available from:https://www.aapcpublishing.net/the-outlook/stress-of-parenting-achild-with-autism-spectrum-or-related-diorders.aspx

[6] Gary J, Rubin SN. Global awareness of autism spectrum disorder: Impact and interventions. Ameri can Psychology Association; 2015. Available from: http://www.apa.org/international/pi/2015/06/ autism-spectrum.aspx. 